\section{Chromosome abnormalities}

SIR - The News and Views article by R.G. Edwards (Nature 26 May, p.283) draws attention to the fact that the incidence of various types of chromosomal abnormalities in human pre-implantation stages of development has yet to be established, although the possibility exists that the incidence of such embryos could be very high. The article was related to the report by Angell et al. in the same issue (p.336) of the finding of both haploid and aneuploid conceptuses following human in vitro fertilization. The single 7-cell haploid embryo that was successfully karyotyped was classified as maternal in origin and $22 \mathrm{X}$, -17 . This observation clearly demonstrated that haploidy due to gynogenesis or more likely parthenogenesis, even when associated with autosomal nullisomy, is compatible with at least a limited degree of viability.

Conditions which might induce parthenogenetic activation, such as the general anaesthetic given to the mother, or the nitrous oxide used for inducing pneumoperitoneum during laparoscopy, were present. Indeed, various studies have clearly demonstrated that a wide range of anaesthetic agents are capable of inducing parthenogenetic activation in mammalian ova. Once activated by this means, development beyond implantation of presumptive haploid embryos has even been reported ${ }^{1}$. Exposure of mammalian eggs to a sperm suspension may also induce parthenogenetic rather than fertilized development ${ }^{2}$, the various enzymes released by sperm from the acrosome region providing the necessary activating stimulus. In the mouse, post-ovulatory ageing of the oocyte before exposure to a sperm suspension undoubtedly facilitates parthenogenetic activation, and this factor is equally applicable following exposure to a wide range of activating stimuli.

However, it has yet to be established whether human oocytes are equally or possibly more sensitive than rodent eggs to these activating stimuli, at relatively shorter time intervals after ovulation.

Possibly of greater interest, however, was the high incidence of aneuploidy reported by Angell et al. While it is possible that a significant proportion of aneuploid oocytes may be ovulated in man, this would clearly be at variance with the stimulation observed in other mammalian species, where the incidence following both in vivo and in vitro fertilization is extremely low. This suggests that the methodology associated with the collection and fertilization of the material in their study might play a significant part in elevating the true incidence of meiotic non-disjunction.

The exposure of recently fertilized mouse eggs to ethanol while they were completing the second meiotic division induces a relatively high incidence of non- disjunction in the oocyte-derived but not the sperm-derived chromosomes ${ }^{3}$. A similar effect is also observed when mice are anaesthetized close to the time of the HCG injection during induced ovulation ${ }^{4}$. M.H. KAUFMAN

Department of Anatomy,

University of Cambridge,

Cambridge CBZ $3 D Y$, UK

1. Kaufman, M.H. J. Embryol. exp. Morph. 33, 941-946 (1975).

2. Kaufman, M.H. Nature 242, 475-476 (1973).

3. Kaufman, M.H. Nature 302, 258-260 (1983).

4. Kaufman, M.H. Devl Mammals 2, 137-163 (1977)

\section{ARC's role}

SIR - Your leading article on the Agricultural Genetics Company (AGC) (Nature 28 July, p.294) calls for clarification of my council's position. You are correct to emphasize the need for a strong flow of innovation between publicly-funded laboratories and British industry. This is what led the Agricultural Research Council (ARC) to enter into the agreement with AGC. By its nature, discovery in plant molecular biology needs further development and scale-up before it can be taken up by the agricultural supply industry. ARC scientists should concentrate on research and not be distracted by the need to study scale-up development nor to negotiate exploitation arrangements project by project. In ARC's judgement, AGC, with its specialist, technical and commercial staff and facilities, is just what is needed to bridge the technological gap between ARC laboratories and British industry. AGC's role in biotechnology can be likened to that of the Agricultural Development and Advisory Service in transferring ARC technology in more conventional fields of animal and crop husbandry. If, however, experience shows that the special relationship with AGCimpedes the flow of innovation to the generality of industry, the problem would have to be addressed in the first review of the agreement, due in 1986.

Neither AGC nor my council intends the special relationship to exclude other companies continuing to collaborate with ARC institutes. As always, in their discussions with industry, ARC scientists must guard against the premature disclosure of potentially valuable commercial property and know-how. AGC recognizes that it cannot do everything in the field and so may be expected to have a general policy of welcoming ARC links with other companies and of exploring opportunities for joint ventures with those companies.

Nor is there any question that AGC will attempt to direct or influence publiclyfunded research. That will remain the responsibility of my council and institute directors. It is likely, however, that AGC will fund with ARC institutes, on a full cost basis, additional work relevant to its commercial objectives, as do other companies.

RALPH RILEY

Agricultural Research Council,

(Secretary)

160 Great Portland Street,

London WIN 6DT, UK

\section{$\mathrm{CO}_{2}$ euthanasia}

SIR - I was startled to see, in a letter published in Nature last year, a casual mention of the fact that experimental rats had been killed by immersion in 100 per cent $\mathrm{CO}_{2}$. I have since discovered that this is a common method of killing animals, and is generally believed to be humane ${ }^{1}$.

Carbon dioxide is far from being an inert gas. Nunn, in his book Applied Respiratory Physiology ${ }^{2}$, devotes a chapter to its effects, noting that "few subjects in the field of physiology are as complicated" and listing five major effects on the brain, as well as major effects on the endocrine, respiratory and circulatory systems, the kidney and the electrolyte levels. Rebreathing from a closed system, so that the $\mathrm{CO}_{2}$ levels steadily rise, causes the respiration to become so deep and fast as to be literally unbearable; the experiment is invariably terminated by the subject long before unconsciousness occurs. Although inhalation of 30 per cent $\mathrm{CO}_{2}$ produces anaesthesia (through a narcotic effect and also by lowering the brain intracellular $p \mathrm{H}$ ), this has never been popular as a human anaesthetic because of the frequency of convulsions. There appear to be no recorded experiments in which a human volunteer has inhaled 100 per cent $\mathrm{CO}_{2}$ to the point of unconsciousness, and I have been unable to find a knowledgeable doctor willing to supervise that experiment on me. So there seem to be doubts, both physiological and humanitarian, over the use of 100 per cent $\mathrm{CO}_{2}$ for killing animals.

In contrast, many human volunteers (including myself) have experienced simple oxygen deprivation, which causes no subjective suffering and few physiological consequences. Unconsciousness supervenes after a few minutes, unexpectedly and peacefully. Oxygen deprivation can be arranged by re-breathing via a filter that removes exhaled $\mathrm{CO}_{2}$, by inhalation of carbon monoxide, or by inhaling nitrogen. The last of these could be easily adapted for small animal work and would be safe for the operator. It might not be as quick as $\mathrm{CO}_{2}$, but it would certainly upset the animal's physiology less and might well be more humane.

DAVID L.J. FREED Department of Bacteriology and Virology, University of Manchester, Manchester M13 9PT, UK

1. Baker, H.J., Lindsey, J.R. \& Weisbroth, S.H. The Laboratory Rat 12, 24-26 (Academic, New York, 1980)

2. Nunn, J.F. Applied Respiratory Physiology 2nd edn, 361 (Butterworth, London, 1977). 